\title{
Norma social y ética privada: el adulterio femenino en Cervantes
}

\author{
Steven Hutchinson*
}

No yerran las mujeres en modo alguno cuando rechazan las normas de vida que rigen el mundo, pues hanlas hecho los hombres sin contar con ellas.

Michel DE Montaigne, «Sobre unos versos de Virgilio»

L'adultère n'est un mal qu'autant qu'il est un vol mais on ne vole point ce qu'on vous donne.

VolTaIRe, Dictionnaire philosophique, «adultère»

Greater love than this, he said, no man hath that a man lay down his wife for his friend.

James JoyCE, Ulysses, cap. 14

El 12 de enero de 1643 José Pellicer cuenta en sus Avisos, al parecer sin extrañamiento o escándalo, el siguiente incidente:

Marcos de Encinillas, Aposentador de Palacio i vn Hombre muy bien recibido en él, i querido de los Reyes, mató de noche a su Muger i se huyó a sagrado. Dicen que tuvo celos de vn Enano de Palacio i que por la mañana le aguardó para matarle. Pero sucedió que, haviendo madrugado el Príncipe Nuestro Señor, al Campo havía ido con Su Alteça, con que se escapó. Si bien la Voz vniversal es que la difunta era vna Santa i que murió inocente de las Sospechas ${ }^{1}$.

* University of Wisconsin-Madison.

1. José Pellicer, Avisos (17 de mayo de 1639-29 de noviembre de 1644), vol. 1, ed. Jean-Claude Chevalier y Lucien Clare, Paris, Éditions Hispaniques, 2002, p. 464. 
Parece así que era lo más natural del mundo matar a la propia esposa en las mismas barbas del rey, y además intentar quitar de en medio a un enano favorito de su Majestad — quizás alguno de los retratados por Velázquez- en contra de la ley, en la casa del rey, y en aras de la honra y, al fin y al cabo, todo por sospechas infundadas. Este no es el único caso que se asoma a las páginas de la obra de Pellicer, cuya materia, como todos saben, es esencialmente política y, por lo tanto, no se prodiga en casos de faldas ni otras intimidades vergonzantes. No obstante, también se nos cuenta el caso del sastre del rey que muere por encargo de otro empleado de la casa real que además tiene el detalle de llevar a su mujer a confesarse antes de ejecutarla, sólo porque le parecía que el sastre la miraba con cierta alegría; el caso es que la mujer se escapa gracias al confesor y por eso tal vez Pellicer considera esta noticia digna de su pluma ${ }^{2}$. Como ejemplo análogo, en una carta fechada el Jueves Santo de 1637 se cuenta que un escribano real, «habiendo aguardado ocasión y día en que su mujer había confesado y comulgado, le dio garrote en su casa haciendo oficio de verdugo y pidiéndole perdón, y esto por muy leves sospechas de que era adúltera $»^{3}$. Contrario a lo que se ha creído tradicionalmente, los dramas de honor no son patrimonio mayoritario de la literatura. María Helena Sánchez Ortega se pregunta como historiadora hasta qué punto son un tópico literario y concluye que no hay duda de una realidad social ampliamente documentada, poco estudiada en las fuentes históricas, y posiblemente por lo común, poco recogida en noticias, casos legales, archivos y diversas fuentes históricas ${ }^{4}$. En efecto, como ya atestiguan muchos estudiosos, semejantes casos abundan en los archivos y no dejan lugar a dudas.

Un caso que pone de relieve de forma clarísima la incidencia del drama de honor en la vida real es el que sucedió en La Plata (Bolivia) en 1595, tal y como se recoge en el sumario abierto tras el crimen y recogido en el Archivo Nacional de Bolivia. Ese año el oidor Gaspar de Peralta, juez de la Audiencia Real de Charcas, acudió a casa de su vecino Fernando de Medina, secretario de la Audiencia, y encontró a éste ante el cadáver sangriento de su esposa a la que acusaba de adulterio. Lo extraordinario del caso es que el propio Gaspar de Peralta había asesinado a su propia mujer y a su supuesto amante diez años antes; homicidios confesos de los que fue exonerado por considerarlos dentro de la legalidad vigente que regulaba las venganzas de honor ${ }^{5}$.

De hecho, la ley permitía la ejecución instantánea de la esposa y su amante si eran sorprendidos in fraganti. Pocos lectores de la autobiografía del capitán

2. José Pellicer, op. cit., p. 28.

3. Francisco Tomás y Valiente, El derecho penal de la monarquía absoluta (siglos XVI-XVIIXVIII), Madrid, Editorial Tecnos, 1969, p. 73, recoge este ejemplo de La corte y la monarquía de España en 1636 y 1637. Colección de cartas inéditas publicadas por Antonio Rodríquez Villa.

4. María Helena Sánchez Ortega, La mujer y la sexualidad en el antiguo régimen. La perspectiva inquisitorial, Madrid, Akal, 1992, pp. 98-99.

5. Thomas A. Abercrombie, «Affairs of the courtroom: Fernando de Medina confesses to killing his wife», en Colonial Lives: Documents on Latin American History, 1550-1850, ed. Richard Boyer y Geoffrey Spurling, Oxford, Oxford University Press, 2000, pp. 54-76. 
Alonso de Contreras recordarán que él mismo mata a su mujer y a su mejor amigo ( $\mathrm{y}$ no he visto ninguna mención de este caso en los estudios que he consultado). Contreras cuenta muy brevemente cómo conoce en Palermo a una viuda madrileña y poco después se casa con ella. En sus palabras:

\begin{abstract}
Estuvimos casados con mucho gusto más de año y medio, quiriéndonos el uno al otro, y cierto que era tanto el respeto que la tenía, que á veces fuera de casa no me quería cubrir la cabeza delante de ella; tanto la estimaba. En suma: yo tenía un amigo que le hubiera fiado el alma; entraba en mi casa como yo mismo, y fue tan ruín que no mirando á la gran amistad que había entre los dos, comenzó á poner los ojos en mi mujer que yo tanto amaba, y aunque yo vía algunas cosas de más cuidado en el hombre de lo ordinario, no pensé en tal cosa...
\end{abstract}

Pero avisado por un criado, aguarda la ocasión:

yo que no dormía, procuré andar al descuido con cuidado, hasta que su fortuna los trujo á que los cogí juntos una mañana y murieron; téngalos Dios en el cielo si en aquel trance se arrepintieron. Las circunstancias son muchas y esto lo escribo de mala gana. Sólo diré que de cuanta hacienda había no tomé un dinero [...] y la hacienda gozó un hijo del primer marido ${ }^{6}$.

Varias cosas llaman la atención en este relato: (1) Contreras insiste en el amor mutuo y felicidad de su mujer y él, y en su gran respeto hacia ella; (2) el amante no es otro que un íntimo amigo de Contreras, y por lo tanto traidor; (3) no hay ningún triunfalismo, ninguna catarsis en la actitud de Contreras, ni tampoco autojustificación, sino que al contrario le duele escribir de esto y más bien suprime detalles; (4) el propio Contreras en su manuscrito suaviza el texto al tachar las palabras «y los maté» y escribir en su lugar «y murieron», neutralizando así su propio protagonismo en el desenlace; (5) precisa que él no quiso aprovechar económicamente la muerte de su mujer.

Otro ejemplo comparable se encuentra en Conquista y descubrimiento del nuevo reino de Granada (El carnero) (1639), de Juan Rodríguez Freyle, donde se cuentan, entre otras cosas, varias historias de asesinato de mujeres por parte de sus maridos e incluso un caso de asesinato de dos maridos en serie por parte de la mujer. Una de estas historias (sobre sucesos ocurridos en 1584) se conforma al pie de la letra con la venganza en privado estipulada por la ley. Se enteró el marido del adulterio, fingió irse de viaje para luego sorprender a su mujer con el amante: dice el texto que el marido «matóla junto al muerto amigo, dejándolos juntos», antes de llamar a la justicia ${ }^{7}$.

Estamos tan acostumbrados a leer sobre esposas que conviven con la posibilidad de la muerte violenta a manos de sus maridos que tendemos a

6. Alonso de Contreras, Vida del capitán Contreras, ed. Joan Estruch, Barcelona, Fontamara, 1982, pp. 96-97 (cap. 8).

7. Juan Rodríguez Freyle, Conquista y descubrimiento del Nuevo Reino de Granada, ed. Jaime Delgado, Madrid, Historia 16, 1986, pp. 209-210. 
despreciar este detalle casi como si fuera un lugar común o una forma más o menos hiperbólica de referirse a los peligros del juego de la honra. En efecto, cuando una mujer se casaba, jugaba sus cartas y sabía muy bien que la sospecha de adulterio a veces era más que suficiente para perder la vida. Por supuesto, hay que tener cierta cautela a la hora de generalizar sobre las actitudes de toda una sociedad hacia temas tan cargados como la honra y el adulterio. La clase social parece haber influido algo más de lo que admite el teatro del XVII, ya que abundan casos de maridos pobres que hacen de alcahuetes o que por lo menos consienten en el adulterio de sus mujeres ${ }^{8}$, lo cual pone de relieve las alabanzas que expresa don Quijote hacia el pobre honrado y la bella esposa del mismo (II, 22). En el polo opuesto a los dramas de honor, la literatura de los Siglos de Oro ofrece multitud de sátiras, parodias y anécdotas burlescas centrándose en adulterios, cuernos, etc., que sirven para atenuar aquella imagen tan implacable de una sociedad obsesionada por la honra. Pero también es cierto que en los géneros más serios el adulterio tiende a considerarse un mal absoluto, una transgresión tan severa de las normas de la moral, que no se cuestiona ni se analiza en su casuística. El adulterio así se condena sin ambages e implícitamente se sanciona la norma social. Y es aquí donde Cervantes se distingue de otros muchos escritores de la época ya que suele buscar la causa del adulterio femenino en la conducta de los maridos. Ni siquiera se puede decir que el adulterio sea un mal relativo en Cervantes, porque no siempre es un mal. Como ya en 1925 afirmaba Américo Castro con admirable contundencia: «Cervantes no ha presentado nunca un adulterio que en el fondo no apruebe o disculpe» ${ }^{9}$. En entremeses como El viejo celoso y La cueva de Salamanca se muestra no sólo comprensión sino complicidad hacia las mujeres que optan por tener amantes. En las novelas cortas El celoso extremeño y El curioso impertinente también se encuentra una amplia disculpa del adulterio por el comportamiento de los maridos y a la vez no se ocultan los instintos de asesinato latentes en sus celos, dejando entrever el trasfondo legal que respalda semejante crueldad. En el Persiles, y concretamente en la historia de Ortel Banedre y su mujer Luisa la Talaverana, si bien no se aplaude la liviandad de la adúltera, se enfatiza la idiotez de Ortel al comprar como esposa a una muchacha enamorada de otro y, sobre todo, la insensatez y la maldad de los instintos de venganza, incluso cuando éstos son plenamente apoyados por la ley ${ }^{10}$. Así, el enorme peligro que corrían las mujeres casadas

8. Ver, por ejemplo, Tomás y Valiente, op. cit., pp. 75-76.

9. Américo Castro, El pensamiento de Cervantes, Barcelona, Crítica, 1987, p. 242.

10. Los consejos de Periandro a Ortel Banedre parecen plasmar una actitud más generalmente cervantina:

¿Qué os puede suceder, como digo, sino hacer más público vuestro agravio? Porque las venganzas castigan, pero no quitan las culpas; $\mathrm{y}$ las que en estos casos se cometen, como la enmienda no proceda de la voluntad, siempre se están en pie, y siempre están vivas en las memorias de las gentes, a lo menos en tanto que vive el agraviado. Así que, señor, volved en vos, $\mathrm{y}$, dando lugar a la misericordia, no corráis tras la justicia. Y no os aconsejo por esto a que perdonéis a vuestra mujer, para volvella a vuestra casa, que a esto no hay ley que 
de la época se refleja en el siniestro substrato de estas novelas, pero los enfoques y desenlaces cervantinos se desvían completamente de la rígida ortodoxia y codificación legal de asuntos de honra. Convendría anotar también, como han hecho varios estudiosos, que los religiosos de la época desde frailes hasta papas condenaban el adulterio sin cuestionar sus causas, pero a menudo se oponían enérgicamente a las venganzas sangrientas sancionadas por la ley civil $^{11}$. Recordemos, además, que para Cervantes la venganza en general se plantea como un problema y nunca una solución ${ }^{12}$.

Como indica Francisco Tomás y Valiente, las leyes sobre el adulterio varían poco desde Alfonso X hasta el siglo XVIII:

una ley del Fuero Real, en cierto modo confirmada por otra de las de Toro, e incluida en las Recopilaciones oficiales, declaraba que los adúlteros fueran puestos «en poder del marido, y éste faga dellos lo que quisiera». La única limitación era la igualdad de trato que el marido debía dar a su mujer y al adúltero (es decir, matar a ambos, o dejar vivos a los dos) ${ }^{13}$.

os obligue; lo que os aconsejo es que la dejéis, que es el mayor castigo que podréis darle. Vivid lejos della, y viviréis; lo que no haréis estando juntos, porque moriréis continuo. La ley del repudio fue muy usada entre los romanos; y, puesto que sería mayor caridad perdonarla, recogerla, sufrirla y aconsejarla, es menester tomar el pulso a la paciencia y poner en un punto estremado a la discreción, de la cual pocos se pueden fiar en esta vida, y más cuando la contrastan inconvenientes tantos y tan pesados. Y, finalmente, quiero que consideréis que vais a hacer un pecado mortal en quitarles las vidas, que no se ha de cometer por todas las ganancias que la honra del mundo ofrezca (Persiles III,7,501-02).

11. Tomás y Valiente, op. cit., p. 71, se refiere a la condena por parte del papa Alejandro VII de las venganzas de los maridos ofendidos. Mariló Vigil (La vida de las mujeres en los siglos XVI y XVII, Madrid, Siglo XXI, 1986, pp. 148-153) escribe más ampliamente sobre las actitudes de los religiosos y relata un interesante incidente donde se vislumbra una complicidad entre los frailes y el pueblo en contra del marido:

En las Memorias eclesiásticas y seculares de Sevilla se cuenta el caso que sucedió allí en 1629. Un catalán llamado Cosme, de oficio sastre, acusó de adulterio a su mujer con un oficial. Logró sentencia de culpabilidad y el 25 de septiembre se los entregaron en público cadalso. Los frailes cercaron al marido para convencerle de que perdonase y él se negaba, pero se promovió un tumulto entre los frailes y la multitud, y comenzaron a decir que había otorgado el perdón, aprovechando lo cual, los frailes sacaron a la mujer de allí para llevarla al convento de San Francisco e hicieron escapar al mozo por otro lado. Aunque el marido gritaba y hacía señas negativamente, de donde se compuso una copla que fue popular por mucho tiempo en Sevilla: «Todos le ruegan a Cosme / que perdone a su mujer; / y él responde con el dedo: / señores, no puede ser» (pp. 150-151).

En su edición del Persiles (5. ${ }^{\text {a }}$ ed., Madrid, Cátedra, 2004), p. 501 (III,7), Carlos Romero cuenta otro caso ocurrido en Sevilla, éste a mediados del XVI, donde los clérigos también asumieron protagonismo al oponerse a que se consumara el acto vengativo, pero sin éxito. Por otro lado, ya hemos visto cómo interviene un confesor a favor de la mujer en un caso narrado por Pellicer.

12. Este tema se explora en mi libro Economía ética en Cervantes, Alcalá, Centro de Estudios Cervantinos, 2001, pp. 147-162.

13. Tomás y Valiente, op. cit., p. 71. El Diccionario de Autoridades de 1726 (bajo «adulterio») cita una de las leyes vigentes (Recop. lib. 8. tit. 20. ley 1): «Si muger casada ficiere adulterio, ella y el adulterador ambos sean en poder del marido.» Y añade: «El marido no pueda acusar de adulterio a uno de los adúlteros siendo vivos, mas que a ambos adúltero, y adúltera los haya de acusar, o a ninguno.» 
Si el marido optaba por acusar a su mujer ante un juez, y si se comprobaba que era verdad, la entrega al marido se convertía en un gran espectáculo público. Esta práctica se refleja en el Persiles donde Periandro le pregunta al agraviado marido Ortel:

¿Qué pensáis que os sucederá cuando la justicia os entregue a vuestros enemigos, atados y rendidos, encima de un teatro público, a la vista de infinitas gentes, y a vos, blandiendo el cuchillo encima del cadahalso, amenazando el segarles las gargantas, como si pudiera su sangre limpiar, como vos decís, vuestra honra? (III,7,501) ${ }^{14}$.

Lo más habitual, sin embargo, era «a secreto agravio secreta venganza», arreglándose el asunto en casa sin testigos, y de semejantes casos están llenos los $\operatorname{archivos}^{15}$.

El hecho de recordar la legislación y algunos casos de «justicia» tanto pública como privada nos indica que la postura cervantina de no condenar el adulterio femenino no es simplemente una reacción literaria ante la ortodoxia de otros escritores y, en concreto, contra el cansado género de dramas de honor. La actitud cervantina sale del ámbito de un debate literario para meterse de lleno en un problema vital de su tiempo.

En El celoso extremeño Carrizales, al ver a «los nuevos adúlteros enlazados en la red de sus brazos» (como dirá el narrador), tiene la «determinación honrosa y necesaria» de tomar «venganza que aquella grande maldad requería si se hallara con armas para poder tomarla; y así, determinó volverse a su aposento a tomar una daga, y volver a sacar las manchas de su honra con sangre de sus dos enemigos, y aun con toda aquella de toda la gente de su casa» (p. 130). Pero se desmaya por angustia y después se venga a la inversa en su testamento al doblar la dote de Leonora y mandarle que se case después con Loaysa. Muy sabido es que en la versión de hacia 1606 hay sin duda adulterio, mientras que en la versión definitiva de 1613, contra toda verosimilitud, Leonora se resiste en el último momento y los amantes se quedan

14. Como ya he indicado, la documentación de la época confirma la existencia de escenas como ésta. El siguiente ejemplo — de Sevilla en 1555- recontado por Carlos Romero en su edición del Persiles parece captar la esencia de este acto público:

Silvestre de Angulo, tabernero sevillano, probó ante el juez el adulterio de su mujer con un mulato. De acuerdo con la ley, los «culpables» fueron entregados al marido para que éste hiciese justicia. Fue levantado un cadalso en la plaza de San Francisco, sobre el que los reos, de rodillas, esperaban, los ojos vendados con el velo de la mujer, que el verdugo había cortado en dos mitades. Llegó Angulo, seguido de religiosos, los cuales, con el crucifijo en la mano, le pidieron perdón para los dos desgraciados. Las súplicas fueron inútiles. El tabernero sacó un cuchillo de una bota y empezó a herir, primero a la mujer, después al mulato, hasta que no los vio muertos. Entonces se quitó el sombrero ante la multitud y gritó, con aire triunfal: «FFuera cuernos!» (III, 7,501).

15. Ver, entre otros, Renato Barahona, Sex Crimes, Honour, and the Law in Early Modern Spain: Vizcaya, 1528-1735, Toronto, University of Toronto Press, 2003, passim; Tomás y Valiente, op. cit., p. 72; Mariló Vigil, op. cit., p. 152; María Helena Sánchez Ortega, op. cit., p. 99. 
dormidos, dejando perplejo al narrador, quien declara en la última frase de la novela: «Sólo no sé qué fue la causa que Leonora no puso más ahínco en disculparse y dar a entender a su celoso marido cuán limpia y sin ofensa había quedado en aquel suceso» (p. 135). Quizás lo más asombroso de esta novela sea que la culpa se distribuye por todos los personajes de la novela - empezando por el propio Carrizales, quien la asume explícitamente - con la excepción de la propia adúltera, quien mantiene su inocencia de niña. A lo mejor los cambios efectuados por Cervantes responden menos a presiones de índole contrarreformista (como afirma Américo Castro ${ }^{16}$ ) que a un deseo de desadulterar a Leonora y así conservar su inocencia, situando su adulterio en una intención anterior pero no en su última voluntad o en el acto sexual. Recordemos que, como esposa, Leonora se ha enterado poco de los llamados «frutos del matrimonio», y que, encerrada en un mundo bastante infantil, ha sido la menos implicada en el largo proceso de seducción iniciada por Loaysa en el que participaron el negro eunuco y todas las mujeres de la casa, sobre todo la señora Marialonso. Por los trucos de la magia cervantina, la única no culpable sería la que tradicionalmente llevaría todo el peso del agravio: la adúltera. Incluso se puede pasar de lo moral a lo extramoral y disculpar la comprensible conducta de todos desde Carrizales, sujeto a los tiránicos celos, hasta todas las mujeres encerradas, por «ser la privación / causa de apetito» (como alegremente canta Marialonso). Sea como sea, el hecho es que la crítica no condena a Leonora por adúltera ni siente la tentación moralista de invocar el sacramento de matrimonio.

Ha ocurrido todo lo contrario con Camila en El curioso impertinente. Al margen de la intransigencia del código de la honra y de las leyes al respecto, ella también tiene un marido cuyo comportamiento puede exonerarla de cualquier culpabilidad, un marido que (como Carrizales) acaba asumiendo toda la culpa de lo ocurrido. Aunque la crítica ha examinado esta novela desde numerosos enfoques y ha mostrado poca simpatía hacia Anselmo en particular, noto dos tendencias dominantes con respecto a Camila: o se la culpa por ser adúltera, o se la minimiza. Pocas veces se la ha visto en clave de mujer, y pocas veces se han sabido apreciar sus cualidades y capacidades. Salvo en casos excepcionales como el de Dulcinea, un importante indicio de la importancia de un personaje se mide en el espacio que se le concede para hablar. Después de Dorotea, la mujer que más habla en la primera parte del Quijote es Camila: más que Marcela, Luscinda, Leonela, Zoraida, doña Clara, la sobrina, el ama, Maritornes, etc. ${ }^{17}$. Téngase en cuenta también que Camila dialoga con Leonela, la quinta en esta lista, y así comparte espacio con ella. Además, como afirma Howard Mancing siguiendo a Bajtín, si lo que más importa es el número de enunciados y no la extensión de los mismos,

16. Américo Castro, op. cit., pp. 243-244.

17. Las relevantes estadísticas se ofrecen en Alicia Redondo Goicoechea, «Cuánto hablan las mujeres del Quijote, los casos de Marcela y Dorotea», en El "Quijote» en clave de mujer/es, ed. Fanny Rubio, Madrid, Editorial Complutense, 2005, p. 448. 
el personaje que más enunciados pronuncia en el Curioso es Camila, lo cual señalaría su protagonismo en esta novela ${ }^{18}$.

Por otro lado, observemos que Camila tarda mucho en hablar. No abre la boca en todo ese interminable capítulo 33 donde Anselmo y Lotario hablan de ella, de la naturaleza de la mujer, del matrimonio y de la peculiar enfermedad que sufre el marido. Las únicas palabras suyas antes de ceder a los requerimientos de Lotario se encuentran en una breve y desesperada carta a Anselmo. Nunca oímos la voz de la mujer que tan bien se ha portado según las reglas del juego; oímos a Camila únicamente como adúltera, es decir, como infiel esposa y apasionada amante, lo cual parece haber condicionado la percepción de muchos lectores. Sólo nace como personaje literario en el momento en que empieza a sentir conflicto como sujeto, y a partir de allí llega a ser, a mi juicio, uno de los personajes más extraordinarios del Quijote.

Veamos algunos ejemplos de cómo se la ha percibido. En las 64 páginas de bellas meditaciones sobre las mujeres del Quijote, Concha Espina se refiere escuetamente a «la flaqueza de Camila, justo castigo de El curioso impertinente» ${ }^{19}-\mathrm{y}$ no vuelve a hacerle caso. En su también extenso análisis de las mujeres retratadas en el Quijote, Carmen Castro la descarta citando el quiasmo del propio narrador: «Rindióse Camila; Camila se rindió» y añade: «Camila es sólo de carne. Camila es sólo un personaje que se deja halagar. Es un personaje de cuento, no un personaje de novela. ${ }^{20}{ }^{2}$ Francisco Ayala postula un hipotético homoerotismo en la motivación de Anselmo, pero acaba adoptando una postura hipermoralista al hablar de la «pasión pecaminosa [e indigna de una mujer noble] que por lo tanto no podría conducir a término feliz»; concluye que «el interés principal de Cervantes no está dirigido hacia lo psicológico, sino que apunta a lo moral»: en concreto, «se trata de un problema de conducta en el matrimonio» ${ }^{21}$. Y claro, si el propósito cervantino es examinar la conducta en el matrimonio, Camila sólo puede salir perdiendo, aunque con alguna disculpa por los procedimientos de su marido. Son varios los críticos que han seguido las pautas moralistas de Ayala, todos ellos convencidos de que esta novela en el fondo trata de una prueba de fidelidad matrimonial. El narrador no ha tenido poca responsabilidad en (des)orientar a muchos lectores hacia el supuesto sentido del argumento. Este narrador, el más moralizante y por lo tanto anticervantino de toda la obra de Cervantes - los perros Berganza y Cipión lo calificarían de predicador-, introduce un lenguaje moral y una tropología militar que ha contagiado a muchos críticos, quienes a su vez hablan de la honra y la castidad, y dicen que Camila se encuentra asediada, se

18. Howard Mancing, «Camila’s story», Cervantes, 2005, 1, pp. 13-15.

19. Concha Espina, «Mujeres del Quijote» [1916], en El "Quijote» en clave de mujer/es, ed. Fanny Rubio, Madrid, Editorial Complutense, 2005, p. 103.

20. Carmen Castro, «Las mujeres del Quijote. Personajes femeninos de Cervantes» [1953], en El "Quijote» en clave de mujer/es, ed. Fanny Rubio, Madrid, Editorial Complutense, 2005, p. 192.

21. Francisco Ayala, «Los dos amigos», Revista de Occidente X, 1965, pp. 295, 302, 304. 
resiste, se rinde, se entrega, cae, etc. ${ }^{22}$. Todo esto suprime la subjetividad de Camila y remeda el hueco lenguaje del narrador. Sería interesante tachar los muchos juicios de valor con los que sazona el narrador su relato para poder leer sin interferencia ajena lo que dicen y hacen los personajes. Pero ya que este narrador forma parte íntegra de la obra, conviene por lo menos reconocer que no es ni mucho menos el portavoz de Cervantes ${ }^{23}$.

Este narrador es incapaz de ver que en la relación triangular que nos ofrece, cada una de las tres relaciones - y no sólo la amistad y el matrimoniotiene su propio código ético y su modo de valorar las cosas. La «fidelidad» supone algo muy distinto en cada caso, y el valor de la persona varía según los distintos parámetros de cada relación: si el valor de Camila se desploma como esposa, se encarece como amante ${ }^{24}$. Cada relación afecta a las otras dos, y Camila, por su parte - como ya se demuestra en su graciosa conversación con Leonela - se entrega de corazón a sus amores con Lotario a la vez que hace todo lo posible para guardar las apariencias de esposa honrada, consciente de que su vida está en ese equilibrio casi imposible. En un ataque de celos, Lotario le sugiere a Anselmo: «y si fuere la maldad que se puede temer antes que esperar, con silencio, sagacidad y discreción podrás ser el verdugo de tu agravio» (I,34,356). Varias veces en esta novela se alude a la venganza privada que puede tomar el esposo Anselmo, y Camila, aunque no oye estas palabras, sabe muy bien lo que se juega. Cuando la perfidia de Lotario la pone en un peligro extremo, llega el gran momento de Camila con su actuación teatral. Aquí también me parece que buena parte de la crítica, aun cuando a veces ha reconocido su astucia e inteligencia e incluso sus dotes teatrales, ha subestimado a Camila al señalar que se trata de un engaño, un pequeño ardid de consecuencias poco duraderas, la más pequeña de las «cajas chinas» narrativas (como si las hubiera), el fraude de una adúltera, una parodia de Lucrecia, la muerte de la honra de Anselmo, etc. El caso es que

22. En mi artículo «Anselmo y sus adicciones» (en El «Quijote» desde América, ed. Gustavo Illades y James Iffland, Benemérita Universidad Autónoma de Puebla/El Colegio de México, 2006), pp. 126-127, analizo más extensamente el carácter de este narrador y las maneras en que distorsiona la historia que narra.

23. Hasta ahora creo que ha sido la norma en la crítica sobre el Curioso confundir al narrador (o al «moralista» Lotario del capítulo 33) con Cervantes y adoptar una postura fundamentalmente moralista con respecto a Anselmo y Camila, un corolario de lo cual ha sido minimizar a Camila como personaje. No creo que sirva de nada poner de manifiesto las muchas variantes de esta postura que he encontrado, ni indicarlas en bibliografía — estudios que, por otra parte, a menudo aportan valiosos argumentos e intuiciones.

Entre los pocos críticos que han comentado el papel de Camila sin adoptar las perspectivas del narrador figuran Georges Güntert, «El lector defraudado: conocer y creer en El curioso impertinente», Romanistisches Jahrbuch, XXXVII, 1986, p. 279; Yvonne Jehenson, «Masochisma versus machismo or: Camila's re-writing of gender assignations in Cervantes's Tale of Foolish Curiosity», Cervantes XVIII, 1998, 2, pp. 35, 41-47; R. M. Flores, «Formación del personaje femenino en El curioso impertinente», Revista de Estudios Hispánicos, XXXIV, 2000, 2, pp. 331-332, 342-347; y Howard Mancing, op. cit., pp. 9-22.

pp.24. En mi libro Economía ética en Cervantes, pp. 99-107, abordo la cuestión del valor de Camila desde los distintos parámetros que ofrece el texto. 
Camila tendrá que salvarse y procurará a toda costa conservar su relación amorosa con Lotario. Se trata, en suma, de una situación de vida o muerte, y su inspirada performance depende de su gran capacidad de improvisación, comparable a las brillantes actuaciones de Marcela, Dorotea y Ana Félix en momentos de máxima tensión. Nuestro narrador afirma que «como naturalmente tiene la mujer ingenio presto para el bien y para el mal, más que el varón [...], luego al instante halló Camila el modo de remediar tan al parecer inremediable negocio» $(\mathrm{I}, 34,357)$. Yo lo diría de otra manera: Camila, guiada por los imperativos de la supervivencia y el amor, se sitúa más allá del bien y del mal. Supera la lógica de venganza marital al tomar la daga en sus propias manos pues maneja brillantemente el discurso de la honra, prefiriendo matarse a sí misma por la culpa que no tiene, etc. Así pone de manifiesto el absurdo de toda una nefasta ideología en la que ella misma ya no cree, pero que no por ello puede dejar de temer. Tiene al voyeur Anselmo felizmente embobado como un espectador de ópera avant la lettre, pasivo hasta no intervenir para evitar el asesinato de su mejor amigo y el suicidio de su mujer, e intensamente curioso por saber cómo va a acabar el espectáculo. De hecho, Camila deja a todos los presentes - el narrador incluido - con la boca abierta y sin aliento, y consigue por el momento salir suntuosamente del paso y encarrilar su destino. A pesar de la desgracia que ocurre poco después, Camila es el único personaje consecuente con sus acciones. A diferencia de Anselmo y Lotario, tiene la dignidad de no arrepentirse. Mantiene viva la esperanza de seguir con su amante, de modo que no le afecta la muerte de Anselmo, pero sí hace profesión de monja cuando le llegan las noticias de la muerte de Lotario. Como dice el texto, «acabó en breves días la vida a las rigurosas manos de tristezas y melancolías» $(\mathrm{I}, 35,374)$. Los que no están a la altura de las circunstancias son los otros personajes, no Camila.

Una vez que el Curioso se centra en Camila como protagonista y deja en segundo plano a los dos amigos, se vislumbran en este texto algunos gérmenes de aquellas grandes novelas decimonónicas como Ana Karenina o La Regenta que se generan en el adulterio y se enfocan en la conciencia de la mujer entregada a su pasión amorosa. Desde luego son más que patentes las diferencias: v.g., el Curioso es corto y sólo la segunda mitad cuenta la historia de la mujer; Camila no está predispuesta a entrar en relaciones extramatrimoniales y no busca el adulterio; el narrador del Curioso, por su parte, no tiene casi ningún acceso a la subjetividad de Camila y así no nos cuenta cómo ella vive los acontecimientos de su historia. Pero también hay paralelos:

— como esas novelas del XIX, el Curioso es una novela doméstica y (a su manera) urbana;

- una mujer se encuentra en un vacío matrimonial, sufre una crisis y se aventura a vivir el peligroso destino amoroso que se le ofrece;

- asume este destino con todas sus consecuencias, busca su plenitud y procura prolongarlo perfeccionando el arte del engaño como recurso de supervivencia; 
- es muy consciente de los conflictos que produce (o puede producir) su conducta, la cual para ella conduce al «amor» pero desde una perspectiva hostil se calificará como «adulterio» con las connotaciones que este término posee de transgresión, crimen y pecado.

Me parece significativo que a pesar del extenso empleo de la palabra «adulterio» en la época - ejemplos interesantes del cual son las entradas sobre dicho término tanto en el Tesoro como en el Suplemento al Tesoro de Covarrubias $^{25}$ - la palabra «adulterio» y sus derivados aparecen sólo una docena de veces en toda la obra cervantina, y no siempre en sentido propio. Sólo la encontramos una vez en el Quijote, precisamente en el largo discurso de Lotario donde éste habla de «la mujer adúltera» y de las nocivas consecuencias para el marido $(\mathrm{I}, 33,338)$. La única mujer cervantina que se reconoce a sí misma como adúltera (y presa y desterrada) es Luisa la Talaverana en el Persiles - mujer de Ortel Banedre, amante de otros, luego mujer de Bartolomé-, una pobre infeliz hacia la que Constanza, lejos de culparla, se muestra compasiva. Es decir, ésta no será una identidad que asuman las mujeres cervantinas o que tengan que llevar como una marca herrada en la frente. La espada de sus maridos pende encima de ellas, pero todas sobreviven. Los instintos de venganza masculinos o se desvían o se vuelven contra ellos mismos. Y más allá de la culpa o la estigmatización de la mujer se plantea la infidelidad como consecuencia o derivación de complejas relaciones interpersonales en el matrimonio, complejidad que toma en cuenta las opresivas nociones de honor y honra.

Ni que decir tiene que la actitud cervantina dista abismalmente de la que trasciende de los dramas de honor de escritores como Lope o Calderón, sobre todo este último. Como sabemos, una de las posturas más extremistas se encuentra en El médico de su honra donde don Gutierre afirma que «el honor con sangre [...] se lava», y este «médico» le asegura a su nueva desposada doña Leonor que «no está olvidada / la ciencia», a lo que ella responde: «Cura con ella / mi vida, en estando mala» (vv. 2947-49). Allí la esposa interioriza el código de la honra y supedita a él su propia vida. Recordemos que, según Quevedo, el oficio del médico es matar. En La más prudente venganza (Novelas a Marcia Leonarda), el narrador que se presenta como un Lope textualizado matiza una postura intermedia donde afirma, después de contar una historia brutal:

Pues, señora Marcia, aunque las leyes por el justo dolor permiten esta licencia a los maridos, no es ejemplo que nadie debe imitar, aunque aquí

25. En los dos casos Covarrubias, bajo el verbo adulterar, ofrece ejemplos clásicos de castigos de adulterio y procura mediante etimologías reconciliar los dos sentidos de adulterar — por un lado cometer adulterio, y por otro alterar fraudulentamente, contrahacer, falsificar-, siendo para él el segundo un derivado del primero. Una de las etimologías que cita en el Suplemento (la de Festo) capta el concepto en toda su simplicidad: «Adulterium ex eo dictum, quod ad alterius torum accedatur [Se llama adulterio porque uno se mete en la cama de otro]». La etimología de San Isidoro, citada a continuación, añade las nociones de engaño y deshonra. 
se escriba para que lo sea a las mujeres que con desordenado apetito aventuran la vida y la honra a tan breve deleite, en grave ofensa de Dios, de sus padres, de sus esposos y de su fama. Y he sido de parecer siempre que no se lava bien la mancha de la honra del agraviado con la sangre del que le ofendió, porque lo que fue no puede dejar de ser y desatino creer que se quita, porque se mate al ofensor, la ofensa del ofendido ${ }^{26}$.

En efecto, el comienzo y el final de esta cita no contradicen los argumentos de Periandro en el Persiles, pero las palabras que he marcado en cursiva serían impensables en una obra cervantina.

Otro texto áureo que considero bastante paradigmático con respecto al adulterio es El prevenido engañado, sorprendente novela de María de Zayas, que da una serie de viñetas sobre el sexo antes, después y fuera del matrimonio. Se nos presenta a mujeres plenamente sexualizadas que en cada episodio franquean los límites de la castidad que se les imponen: la infidelidad por parte de la mujer acompaña el noviazgo y el matrimonio y se demuestra, muy a pesar del ingenuo protagonista don Fadrique, que en tales circunstancias es muy preferible tener una mujer discreta que una mujer boba e ignorante. Semejante actitud comparte con toda la obra cervantina el reconocimiento de la mujer sexualizada cuya conducta puede sin malicia desbordar la estrechez del matrimonio cuando el carácter o comportamiento del marido lo justifique. Pese a todo lo que se ha escrito sobre el tema, el matrimonio en la obra cervantina es menos una institución que una relación interpersonal: sacramentalizada por la religión, cargada de honra por ciertos estratos de la sociedad, sancionada por la ley como indisoluble e inviolable (por parte de la mujer), pero en última instancia una relación entre dos personas. La pluma de Cervantes, si bien no critica el matrimonio per se, no sale en defensa del matrimonio sino que apoya a la malcasada.

Desde el clima moral transpirinaico, Michel de Montaigne dedica un magnífico ensayo a temas relacionados con el amor y el matrimonio — «Sobre unos versos de Virgilio», Ensayos III, 5- donde plantea una simbiosis entre las relaciones matrimoniales y extramatrimoniales. Las primeras (mariage) se caracterizan idealmente por una sosa, pero dulce amistad, cooperación, un respeto mutuo y sexo moderado; las segundas (amour), por la pasión amorosa y el deleite sexual, pero también por la inestabilidad ${ }^{27}$. Como ocupan dominios bastante distintos, en principio no debe haber mucho conflicto entre ellos. Así Montaigne cuestiona todos los tópicos sobre el adulterio. «Cada uno de vosotros ha puesto los cuernos a alguien» ${ }^{28}$, dice, y como resulta de esto un empate gep. 184.

26. Lope de Vega, Novelas a Marcia Leonarda, ed. Julia Barella, Madrid, Ediciones Júcar, 1988,

27. Michel de Montaigne, «Sobre unos versos de Virgilio», en Ensayos III, 4. ${ }^{\text {a }}$ ed., ed. María Dolores Picazo, trad. Almudena Montojo, Madrid, Cátedra, 2002, pp. 78-80, insiste en una neta distinción entre los dos. «Un buen matrimonio, si es que los hay, rechaza la compañía y las cualidades del amor.» En un matrimonio sano, dice, una esposa nunca cambiaría su lugar por el de una amante de su esposo.

28. Montaigne, op. cit., p. 100. 
neral, conviene repensar las actitudes más nocivas sobre este tema. Una y otra vez señala el injusto tratamiento de las mujeres, como en el siguiente pasaje:

Confesemos la verdad: no hay ninguno de nosotros que no tema más la vergüenza que le viene de los vicios de su mujer que de los suyos; que no se cuide más (¡oh maravillosa caridad!) de la conciencia de su buena esposa que de la suya propia; que no prefiera ser ladrón y sacrílego y que su mujer fuera asesina y herética a que fuera menos casta que su marido ${ }^{29}$.

Apoyándose en tales argumentos y abundantes ejemplos sacados de un enorme conocimiento textual y de toda una vida de observación personal, Montaigne aboga por quitar el estigma de los cuernos, aligerar el adulterio (amour) del peso de la culpa, la honra y el castigo, y aceptar el derecho a amar de las mujeres: «Es por tanto locura tratar de reprimir en las mujeres un deseo que tan ardiente y natural es» ${ }^{30}$.

Aunque la dicotomía que esboza Montaigne entre amor y matrimonio apenas se nota en Cervantes - cuyos personajes en su mayoría sí se casan por amor-, la obra cervantina sintoniza con estos últimos postulados. En los textos cervantinos vemos que el matrimonio no posee valores absolutos, y que en ciertas circunstancias es más que comprensible y justificable el adulterio por parte de la mujer. Por supuesto cuenta en todos sus aspectos la dimensión pública del matrimonio - no porque Cervantes crea o no crea en semejantes valores sino porque constituyen una realidad de su época- pero no se sacrifica del todo a ella la dimensión íntima. Aquí como siempre Cervantes apuesta por lo humano frente a dogmas, prejuicios, leyes e instituciones, y por la comprensión frente a la salvaje imposición de castigos y venganzas.

\section{OBRAS CITADAS}

ABERCROMBIE, Thomas A., "Affairs of the courtroom: Fernando de Medina confesses to killing his wife», en Colonial Lives: Documents on Latin American History, 1550-1850, ed. Richard Boyer y Geoffrey Spurling, Oxford, Oxford University Press, 2000, pp. 54-76. Alfonso X, Las siete partidas, vol. 3, Madrid, Imprenta Real, 1807.

AYALA, Francisco, «Los dos amigos», Revista de Occidente, X, 1965, pp. 287-306.

Barahona, Renato, Sex Crimes, Honour, and the Law in Early Modern Spain: Vizcaya, 1528-1735, Toronto, University of Toronto Press, 2003.

CAlderón de la Barca, Pedro, El médico de su honra, ed. D. W. Cruickshank, Madrid, Castalia, 1989.

CAstro, Américo, El pensamiento de Cervantes, Barcelona, Crítica, 1987.

CAstro, Carmen, «Las mujeres del Quijote. Personajes femeninos de Cervantes» [1953], en $E l$ «Quijote» en clave de mujer/es, ed. Fanny Rubio, Madrid, Editorial Complutense, 2005, pp. 165-206.

29. Montaigne, op. cit., p. 89. Compárese el pasaje siguiente, p. 83: «No hay deseo más acuciante que éste, al cual queremos que sólo ellas resistan, no como si se tratara simplemente de un pecado de la importancia que tiene, sino de uno abominable y execrable, mayor que la irreligión y el parricidio $\mathrm{y}$, sin embargo, nosotros nos entregamos a él sin culpa ni reproche alguno.»

30. Montaigne, op. cit., p. 96. 
Cervantes SaAvedra, Miguel De, Los trabajos de Persiles y Sigismunda, ed. Carlos Romero Muñoz, 5. ${ }^{a}$ ed., Madrid, Cátedra, 2004.

Cervantes SaAvedra, Miguel De, Don Quijote de la Mancha, ed. Francisco Rico, Madrid, Real Academia Española, 2005.

Cervantes SaAvedra, Miguel DE, Novelas ejemplares, ed. Harry Sieber, 2. ${ }^{a}$ ed., 2 vols., Madrid, Cátedra, 1981 [El celoso extremeño, vol. 2, pp. 99-135].

Los códigos españoles concordados y anotados, 12 vols., 2. ${ }^{a}$ ed., Madrid, Antonio de San Martín, 1872.

Contreras, Alonso DE, Vida del capitán Contreras, ed. Joan Estruch, Barcelona, Fontamara, 1982.

CovarRubiAS, Sebastián DE, Tesoro de la lengua castellana o española, ed. Martín de Riquer, Barcelona, Editorial Alta Fulla, 1989.

CovarRuBiAS, Sebastián DE, Suplemento al tesoro de la lengua española castellana, ed. Georgina Dopico y Jacques Lezra, Madrid, Ediciones Polifemo, 2001.

ESPINA, Concha, «Mujeres del Quijote» [1916], en El «Quijote» en clave de mujer/es, ed. Fanny Rubio, Madrid, Editorial Complutense, 2005, pp. 101-164.

FlORES, R. M., «Formación del personaje femenino en El curioso impertinente», Revista de Estudios Hispánicos, XXXIV, 2000, 2, pp. 331-349.

GÜNTERT, Georges, «El lector defraudado: conocer y creer en El curioso impertinente», Romanistisches Jahrbuch, XXXVII, 1986, pp. 264-281.

Hutchinson, Steven, Economía ética en Cervantes, Alcalá, Centro de Estudios Cervantinos, 2001.

HutChInSON, Steven, «Anselmo y sus adicciones», Revista Nueva de Filología Hispánica, en El «Quijote» desde América, ed. Gustavo Illades y James Iffland, Benemérita Universidad Autónoma de Puebla/El Colegio de México, 2006, pp. 119-138.

JEHENSON, Yvonne, «Masochisma versus machismo or: Camila's re-writing of gender assignations in Cervantes's Tale of Foolish Curiosity», Cervantes XVIII, 1998, 2, pp. 26-52.

MANCING, Howard, «Camila's story», Cervantes, 2005, 1, pp. 9-22.

Montaigne, Michel DE, «Sobre unos versos de Virgilio», en Ensayos III, ed. María Dolores Picazo, trad. Almudena Montojo, 4. ${ }^{\text {a }}$ ed., Madrid, Cátedra, 2002, pp. 65-132.

Pellicer De Tovar, José, Avisos (17 de mayo de 1639 - 29 de noviembre de 1644), vol. 1, ed. Jean-Claude Chevalier y Lucien Clare, Paris, Éditions Hispaniques, 2002.

Redondo GoicoecheA, Alicia, «Cuánto hablan las mujeres del Quijote, los casos de Marcela y Dorotea», en El «Quijote» en clave de mujer/es, ed. Fanny Rubio, Madrid, Editorial Complutense, 2005, pp. 445-459.

Rodríguez Freyle, Juan, Conquista y descubrimiento del Nuevo Reino de Granada, ed. Jaime Delgado, Madrid, Historia 16, 1986.

SÁnCHEZ ORTEGA, María Helena, La mujer y la sexualidad en el antiguo régimen. La perspectiva inquisitorial, Madrid, Akal, 1992.

TOMÁs y VAliENTE, Francisco, El derecho penal de la monarquía absoluta (siglos XVIXVII-XVIII), Madrid, Editorial Tecnos, 1969.

Vega CARPIO, Lope DE, Novelas a Marcia Leonarda, ed. Julia Barella, Madrid, Ediciones Júcar, 1988.

VIGIL, Mariló, La vida de las mujeres en los siglos XVI y XVII, Madrid, Siglo XXI, 1986. VOLTAIRE, Dictionnaire philosophique, 〈http://www.voltaire-integral.com/Html/17/adultere.htm〉

ZAYAS SOTOMAYOR, María DE, El prevenido engañado, en Novelas amorosas y ejemplares, ed. Julián Olivares, Madrid, Cátedra, 2000, pp. 295-342.

Recibido: 18 de febrero de 2010

Aceptado: 21 de septiembre de 2010 


\title{
Resumen
}

Contrario a lo que se ha asumido con frecuencia, los dramas de honor no son patrimonio mayoritario de la literatura sino que responden a una realidad social ampliamente documentada. Metiéndose de lleno en un problema vital de su tiempo, Cervantes se distingue de otros muchos escritores de la época ya que suele explorar las causas del adulterio femenino en un contexto muy complejo de disfuncionalidades afectivas que normalmente se ignoran desde los postulados de la honra que privilegia ante todo la incuestionabilidad de la institución matrimonial. En El celoso extremeño se distribuye la culpa por todos los personajes salvo la propia «adúltera». Aunque algo parecido ocurre en El curioso impertinente, la crítica, con frecuencia, se ha conformado con culpar o minimizar a Camila sin apreciar su subjetividad ni sus excepcionales capacidades de amor y supervivencia. Resulta que ella es el único personaje de esta historia coherente en sus acciones. En los textos cervantinos vemos que el matrimonio no posee valores absolutos y que en ciertas circunstancias es más que comprensible y justificable el adulterio por parte de la mujer.

Palabras clave: Cervantes. Matrimonio. Adulterio. Adúltera. Asesinato de mujer. El celoso extremeño. El curioso impertinente. Lope. Calderón. María de Zayas. Montaigne. José Pellicer. Alonso de Contreras. Juan Rodríguez Freyle. Novela decimonónica.

Title: Social norms and private ethics: women's adultery in Cervantes

\begin{abstract}
Contrary to what has often been assumed, honor plays, more than an involuted literary subgenre, respond to a widely documented social reality of wife murders. Delving into a vital problem of his times, Cervantes differs from many other contemporary writers in that he explores the causes of women's adultery in a very complex domain of affective dysfunctionalities that are usually ignored from the postulates of honor, which privileges above all the unquestionability of marriage as an institution. Quite remarkably, in $E l$ celoso extremeño blame is distributed among all the characters except the «adulteress» herself. Although something similar occurs in El curioso impertinente, critics have most often either blamed or belittled Camila, without taking seriously her subjectivity or her exceptional capacity for love and survival. It turns out that she is the only character in this story whose actions are coherent. In these and other Cervantine texts we see that marriage possesses no absolute value and that in certain circumstances a woman's adultery is more than justifiable.
\end{abstract}

Key words: Cervantes. Marriage. Adultery. Adulteress. Wife murder. El celoso extremeño. El curioso impertinente. Lope. Calderón. María de Zayas. Montaigne. José Pellicer. Alonso de Contreras. Juan Rodríguez Freyle. 19th-century novel. 